\title{
Cancer incidence among Hispanic children in the United States
}

\author{
James D. Wilkinson, 1, 2, 3 Alex Gonzalez, ${ }^{2}$ Brad Wohler-Torres, ${ }^{1,} 3$ \\ Lora E. Fleming, 1, 2, 3 Jill MacKinnon, 1, 3 Edward Trapido, 1, 2, 3 \\ Jaclyn Button, ${ }^{1,3}$ and Steven Peace ${ }^{1,3}$
}

Suggested citation

Wilkinson JD, Gonzalez A, Wohler-Torres B, Fleming LE, MacKinnon J, Trapido E, Button J, Peace S. Cancer incidence among Hispanic children in the United States. Rev Panam Salud Publica. 2005; 18(1):5-13.

ABSTRACT Objective. To directly compare cancer incidence among Hispanic children and non-Hispanic white children in California and Florida, two states in the United States of America that include nearly one in three Hispanic children in the country.

Methods. Cross-sectional data for 1988 through 1998 pertaining to all incident pediatric cancer cases (age < 15 years) with race/ethnicity coded as either Hispanic or non-Hispanic white came from the Florida Cancer Data System database and the California Cancer Registry database. The results were expressed as age-standardized incidence rates, standardized to the world standard million population. Hispanic rates and non-Hispanic white rates were compared using standardized incidence ratios (SIRs) with 95\% confidence intervals (95\% CIs.). Results. The SIR for all cancers for Hispanic children compared to non-Hispanic white children was 1.02 (95\% CI: 0.99,1.05). For selected tumor types, SIRs indicated higher incidences among Hispanic children for leukemia (SIR $=1.26 ; 95 \%$ CI: 1.19, 1.34), Hodgkin's lymphoma $(S I R=1.29 ; 95 \% C I: 1.08,1.54)$, and germ cell tumors $(S I R=1.62 ; 95 \%$ CI: $1.34,1.96)$. There were lower incidences for the Hispanic children for central nervous system tumors $(S I R=0.72 ; 95 \% C I: 0.66,0.78)$ and for sympathetic nervous system tumors $(S I R=0.76$; $95 \%$ CI: $0.66,0.87)$. In terms of interstate differences, the incidence of lymphoma, central nervous system tumors, sympathetic nervous system tumors, and malignant bone tumors was highest among Hispanic youth in Florida; the incidence of hepatic tumors was highest among Hispanic youth in California.

Conclusions. While the overall cancer incidence rate among Hispanic children was similar to that for non-Hispanic white children, significant differences for specific tumor types were identified. Since Hispanic ethnicity may be a confounder for other cancer risk factors (e.g., familial, socioeconomic, or environmental), it is recommended that future research into Hispanic pediatric cancer risk investigate these risk factors.

Key words Neoplasms, Hispanic Americans, United States.

1 University of Miami Miller School of Medicine, Florida Cancer Data System, Miami, Florida, United States of America.

2 University of Miami Miller School of Medicine, Department of Epidemiology and Public Health, Miami, Florida, United States of America. Send correspondence to: James D. Wilkinson, Department of Epidemiology and Public Health, Univer- sity of Miami Miller School of Medicine, P.O. Box 016069 (R-669), Miami, Florida 33101, United States of America. Telephone: 305-243-3022 or 305243-5841; fax: 305-243-3384 or 305-243-5544; e-mail: jwilkins@med.miami.edu

3 University of Miami Miller School of Medicine, Sylvester Comprehensive Cancer Center, Miami, Florida, United States of America.
Less than $1 \%$ of all incident cancers in the United States of America occur among children $1-14$ years of age $(1,2)$. Nevertheless, cancer is the most common cause of disease-related mortality for that population, exacting a very 
large toll in terms of productive years of life lost (3). In the increasingly multiethnic society in the United States the characterization of the distribution of childhood cancer among population subgroups is of great interest. This knowledge is essential for determining risk factors, forming etiologic hypotheses, and developing effective targeted cancer prevention and control strategies for pediatric age groups.

Numerous studies in the United States have shown that cancer rates for Hispanic adults are generally lower than those for non-Hispanic white adults (4-11). Findings from studies regarding pediatric cancer risk among Hispanics in the United States have been varied, depending on the tumor types studied, the study population's location (by state), and the age groups studied (12-15). Interpretation and comparison of these reports may be challenging due to important differences in the study time period and duration, sample size, definitions of tumor types, and patient factors (including race and national origin), as well as statistical analysis techniques.

In the 2000 census, of the more than 281 million residents of the United States (excluding Puerto Rico), about 32 million (12\%) identified themselves as Hispanic (16). This figure includes an estimate of nearly 7 million undocumented residents (foreign-born persons who reside in the United States without lawful permission) from Mexico and the rest of Latin America. Approximately 16 million of the Hispanic residents in the United States were foreign-born. The 3.8 million residents of the island of Puerto Rico, 98\% of whom self-identify as Hispanic, are not included in these population estimates.

Nearly one in three Hispanic children (ages <15 years) in the United States resides in either the state of California (in the western part of the United States) or the state of Florida (in the southeastern part of the United States) (17). In California, $44 \%$ of the population less than 18 years of age is Hispanic, while for Florida, the figure is nearly $20 \%$. In California, over $70 \%$ of Hispanic children are of Mexican origin; in Florida, children of Cuban origin comprise nearly a third of the state's Hispanic children (with additional large pediatric populations of Puerto Rican, Central American, and South American ancestry) (18). Most Hispanic children in both California and Florida were born in the United States. Prior cancer epidemiological studies of adult Hispanics of varying national origin living in the United States suggest that the term "Hispanics" encompasses several epidemiologically diverse and possibly unrelated groups of people. Therefore, a study of cancer in the Hispanic pediatric population in these two states would capture a very large sample, as well as represent the diversity within the Hispanic population in the United States.

We therefore decided to directly compare the cancer incidence among Hispanic children and non-Hispanic children in California and Florida, two of the states with the largest Hispanic populations, using combined public use data sets from the two states' respective cancer registries, and using a common time period as well as standard definitions for all study variables, including race/ethnicity and cancer type. We present the results of the analysis of nearly 13000 incident pediatric cancer cases over the most recent 11-year period for which comparable data were available from the two states' cancer registries.

\section{MATERIALS AND METHODS}

The California Cancer Registry (CCR) and the Florida Cancer Data System (FCDS) are statewide, populationbased incidence cancer registries. Both registries are members of the North American Association of Centralized Cancer Registries (NAACCR). NAACCR members use standard case definitions, coding practices, and medical terminology, and they must also meet stringent quality assurance standards. The registries of both California and Florida have received the "Gold" recognition certificate, the highest certification available from NAACCR. The
California and Florida registries use comparable data quality procedures, including multiple edit checks, verification, and validation procedures, before data are entered into the respective databases. The CCR collects nearly 1100 incident cases of cancer in children less than 15 years of age each year, and the FCDS collects more than 400 incident cancer cases in children less than 15 years of age annually.

This study examined all cases of cancer occurring in persons $<15$ years of age that were extracted from the FCDS and CCR public use data sets for the years 1988 through 1998. Since both the FCDS and the CCR have been independently estimated to capture greater than $95 \%$ of all incident cancer cases in their respective states (19), this study was considered to be population-based rather than samplebased.

Race/ethnicity was coded using the more restrictive CCR categorical definition, which assigns cases to one of several mutually exclusive categories: white (non-Hispanic), Hispanic, or one of several other race designations. Previous reports indicate that Hispanics of race other than white constitute about $1.4 \%$ of the California pediatric Hispanic population (14). The FCDS assigns race as a category, and Hispanic origin in a separate data field. Therefore, any FCDS case identified as of Hispanic origin was defined as "Hispanic" (regardless of race), and all cases defined as white but not of Hispanic origin were defined as "white non-Hispanic." Fewer than 4\% of FCDS cases of Hispanic origin are categorized as race other than white (15). All Hispanic cancer cases, regardless of race, were included in our analysis. All cases with race/ethnic categories other than white non-Hispanic or Hispanic, including cases with missing or uncoded race/ethnicity (who made up $<1 \%$ ), were excluded from further analysis. Age at diagnosis was analyzed categorically, with cases assigned to one of three age strata: $0-4$ years, 5-9 years, or 10-14 years of age. In summary, we included in our data analysis all incident cancer cases from 
both states' cancer registries that were diagnosed in children $<15$ years of age and for whom race/ethnicity was coded as either Hispanic or nonHispanic white.

All age-specific incidence rates (including for subpopulations by age, gender, race/ethnicity, and state) were calculated using population denominators from the National Center for Health Statistics of the United States Centers for Disease Control and Prevention, in the city of Atlanta, Georgia. Then, age-standardized incidence rates (ASIRs), standardized to the world standard million population, were calculated for all cancers combined, as well as for the major diagnostic groups of the International Classification of Childhood Cancer (ICCC) and for selected subgroups with substantial numbers of incident cases (20).
The standard errors for the ASIRs were calculated, and the rates for the Hispanic group were then compared to the rates for the white non-Hispanic group, and expressed as standardized incidence ratios (SIRs) with 95\% confidence intervals (CIs). The CIs were constructed based on the logarithmic transformation of the standard error after the method of Breslow and Day (21). Data were analyzed using the SEER*Stat software program, version 5.1.14, from the Surveillance Research Program (National Cancer Institute, Bethesda, Maryland, United States) and Microsoft Excel 2000 (Microsoft, Inc., Redmond, Washington, United States).

This study used only anonymous data sets, with all subject identifiers removed. The study was approved by the University of Miami School of Medicine Human Subjects Institu- tional Review Board (protocol \#02/ 143A).

\section{RESULTS}

From the cases extracted from the two state databases, 9667 cases of cancer from the CCR and 3285 cancer cases from the FCDS met our study criteria for further analysis, for a combined total of 12952 incident cancers in children $<15$ years of age. Table 1 shows the counts of incident cancer cases and ASIRs by ICCC major diagnostic groups and for selected diagnostic subgroups for Hispanic children and non-Hispanic white children $<15$ years of age from 1988 through 1998, as well as the SIRs for Hispanic children, with non-Hispanic whites as the reference group. Table 2 shows the

TABLE 1. Total counts of cancer cases, annual cancer age-standardized incidence rates (ASIRs) per $10^{6}$ person-years, and standardized incidence ratios (SIRs) for Hispanic and non-Hispanic white children $<15$ years of age, 1988-1998, for both states (California and Florida) and both genders combined

\begin{tabular}{|c|c|c|c|c|c|c|c|c|}
\hline \multirow{2}{*}{$\begin{array}{l}\text { ICCC }^{\text {a }} \text { major diagnostic groups } \\
\text { and selected subgroups }\end{array}$} & \multicolumn{3}{|c|}{ Hispanic } & \multicolumn{3}{|c|}{ Non-Hispanic white } & \multirow[b]{2}{*}{$\mathrm{SIR}^{\mathrm{c}}$} & \multirow[b]{2}{*}{$95 \% \mathrm{Cl}^{\mathrm{d}}$} \\
\hline & Count & ASIR & $\mathrm{SE}^{\mathrm{b}}$ & Count & ASIR & SE & & \\
\hline All cancers combined & 5197 & 152.7 & 2.1 & 7755 & 149.5 & 1.7 & 1.02 & $0.99,1.05$ \\
\hline Leukemia & 2096 & 61.5 & 1.3 & 2505 & 48.8 & 1.0 & 1.26 & $1.19,1.34$ \\
\hline Lymphoid leukemia & 1731 & 50.8 & 1.2 & 2024 & 39.5 & 0.9 & 1.29 & $1.21,1.38$ \\
\hline Acute nonlymphocytic leukemia & 280 & 8.2 & 0.5 & 366 & 7.1 & 0.4 & 1.15 & $0.98,1.35$ \\
\hline Lymphoma \& reticuloendothelial & 493 & 14.5 & 0.7 & 760 & 14.0 & 0.5 & 1.04 & $0.91,1.19$ \\
\hline Hodgkin’s lymphoma & 211 & 6.2 & 0.4 & 268 & 4.8 & 0.3 & 1.29 & $1.08,1.54$ \\
\hline Non-Hodgkin's lymphoma & 173 & 5.1 & 0.4 & 317 & 5.9 & 0.3 & 0.86 & $0.71,1.03$ \\
\hline Burkitt's lymphoma & 74 & 2.2 & 0.3 & 136 & 2.5 & 0.2 & 0.88 & $0.65,1.19$ \\
\hline $\mathrm{CNS}^{\mathrm{e}}$, misc., intracranial, intraspinal & 803 & 23.6 & 0.8 & 1706 & 32.6 & 0.8 & 0.72 & $0.66,0.78$ \\
\hline Ependymoma & 69 & 2.0 & 0.2 & 138 & 2.7 & 0.2 & 0.74 & $0.58,0.94$ \\
\hline Astrocytoma & 338 & 9.9 & 0.5 & 905 & 17.2 & 0.6 & 0.58 & $0.52,0.65$ \\
\hline $\mathrm{PNET}^{f}$ & 248 & 7.3 & 0.5 & 421 & 8.1 & 0.4 & 0.90 & $0.76,1.06$ \\
\hline Sympathetic nervous system & 295 & 8.7 & 0.5 & 564 & 11.5 & 0.5 & 0.76 & $0.66,0.87$ \\
\hline Retinoblastoma & 190 & 5.6 & 0.4 & 212 & 4.4 & 0.3 & 1.27 & $1.04,1.54$ \\
\hline Renal tumors & 270 & 7.9 & 0.5 & 448 & 9.0 & 0.4 & 0.88 & $0.76,1.02$ \\
\hline Hepatic tumors & 72 & 2.1 & 0.2 & 103 & 2.1 & 0.2 & 1.00 & - \\
\hline Malignant bone tumors & 208 & 6.1 & 0.4 & 348 & 6.3 & 0.3 & 0.97 & $0.84,1.13$ \\
\hline Osteosarcoma & 129 & 3.8 & 0.3 & 170 & 3.0 & 0.2 & 1.27 & $1.03,1.57$ \\
\hline Ewing's sarcoma & 59 & 1.7 & 0.2 & 157 & 2.8 & 0.2 & 0.61 & $0.48,0.78$ \\
\hline Soft tissue sarcomas & 333 & 9.8 & 0.5 & 477 & 9.1 & 0.4 & 1.08 & $0.94,1.24$ \\
\hline Rhabdomyosarcoma & 144 & 4.2 & 0.4 & 246 & 4.8 & 0.3 & 0.88 & $0.71,1.08$ \\
\hline Germ-cell, trophoblastic, other & 259 & 7.6 & 0.5 & 245 & 4.7 & 0.3 & 1.62 & $1.34,1.96$ \\
\hline Carcinomas, other epithelial & 117 & 3.5 & 0.3 & 314 & 5.7 & 0.3 & 0.61 & $0.51,0.74$ \\
\hline Other and unspecified malignancy & 16 & 0.5 & 0.1 & 34 & 0.7 & 0.1 & 0.71 & $0.44,1.14$ \\
\hline
\end{tabular}

a ICCC $=$ International Classification of Childhood Cancer.

b $\mathrm{SE}=$ standard error.

${ }^{c}$ The standardized incidence ratio $(\mathrm{SIR})$ is referenced to non-Hispanic white children.

${ }^{\mathrm{d}} \mathrm{Cl}=$ confidence interval.

e CNS = central nervous system.

${ }^{f} \mathrm{PNET}=$ primitive neuroectodermal tumor. 
TABLE 2. Annual cancer age-standardized incidence rates (ASIRs) per $10^{6}$ person-years for Hispanic and non-Hispanic white children $<15$ years of age, 1988-1998, by gender for both states (California and Florida) combined

\begin{tabular}{|c|c|c|c|c|c|c|c|c|}
\hline \multirow{2}{*}{$\begin{array}{l}\mathrm{ICCC}^{\mathrm{a}} \text { major diagnostic groups } \\
\text { and selected subgroups }\end{array}$} & \multicolumn{4}{|c|}{ Male } & \multicolumn{4}{|c|}{ Female } \\
\hline & ASIR & $S E^{b}$ & ASIR & SE & ASIR & SE & ASIR & SE \\
\hline All cancers combined & 163.0 & 3.1 & 159.8 & 2.5 & 142.0 & 2.9 & 138.6 & 2.3 \\
\hline Leukemia & 68.0 & 2.0 & 51.6 & 1.4 & 54.8 & 1.8 & 45.8 & 1.4 \\
\hline Lymphoid leukemia & 56.8 & 1.8 & 42.5 & 1.3 & 44.6 & 1.6 & 36.3 & 1.2 \\
\hline Hodgkin's lymphoma & 8.1 & 0.7 & 5.3 & 0.4 & 4.2 & 0.5 & 4.3 & 0.4 \\
\hline Non-Hodgkin's lymphoma & 6.8 & 0.6 & 7.8 & 0.5 & 3.2 & 0.4 & 3.8 & 0.4 \\
\hline Burkitt's lymphoma & 3.3 & 0.4 & 4.1 & 0.4 & 1.0 & 0.2 & 0.9 & 0.2 \\
\hline $\mathrm{CNS}^{\mathrm{c}}$, misc., intracranial, intraspinal & 24.7 & 1.2 & 35.1 & 1.1 & 22.4 & 1.2 & 29.8 & 1.1 \\
\hline Ependymoma & 2.5 & 0.4 & 2.8 & 0.3 & 1.6 & 0.3 & 2.6 & 0.3 \\
\hline Astrocytoma & 9.4 & 0.7 & 18.1 & 0.8 & 10.5 & 0.8 & 16.2 & 0.8 \\
\hline $\mathrm{PNET}^{\mathrm{d}}$ & 8.6 & 0.7 & 9.6 & 0.6 & 5.9 & 0.6 & 6.5 & 0.5 \\
\hline Malignant bone tumors & 5.4 & 0.6 & 6.2 & 0.5 & 6.9 & 0.6 & 6.3 & 0.5 \\
\hline Osteosarcoma & 2.9 & 0.4 & 3.1 & 0.3 & 4.7 & 0.5 & 3.0 & 0.3 \\
\hline Ewing's sarcoma & 1.9 & 0.3 & 2.9 & 0.3 & 1.6 & 0.3 & 2.8 & 0.3 \\
\hline Soft tissue sarcomas & 10.3 & 0.8 & 10.0 & 0.6 & 9.3 & 0.7 & 8.1 & 0.6 \\
\hline Rhabdomyosarcoma & 4.1 & 0.5 & 5.8 & 0.5 & 4.4 & 0.5 & 3.7 & 0.4 \\
\hline Germ-cell, trophoblastic, other & 7.2 & 0.6 & 4.4 & 0.4 & 8.1 & 0.7 & 5.1 & 0.4 \\
\hline Carcinomas, other epithelial & 2.1 & 0.3 & 4.8 & 0.4 & 4.9 & 0.5 & 6.6 & 0.5 \\
\hline Other and unspecified malignancy & 0.5 & 0.2 & 0.7 & 0.2 & 0.5 & 0.2 & 0.7 & 0.2 \\
\hline
\end{tabular}

a ICCC = International Classification of Childhood Cancer.

${ }^{\mathrm{b}} \mathrm{SE}=$ standard error

${ }^{\mathrm{C}} \mathrm{CNS}=$ central nervous system.

${ }^{\mathrm{d}} \mathrm{PNET}=$ primitive neuroectodermal tumor.

ASIRs for Hispanic children and for non-Hispanic white children $<15$ years of age stratified by gender for the same time period. Table 3 shows the age-standardized incidence rates for Hispanic children and for nonHispanic white children $<15$ years of age stratified by the two states, California and Florida, from which the study cases were obtained.

\section{All cancers combined}

The ASIR for all cancers combined did not differ significantly between Hispanic children and non-Hispanic white children, with rates of 152.7 and 149.5 cases per $10^{6}$ person-years (PYs), respectively, and an SIR of 1.02 (95\% CI: $0.99,1.05)$ (Table 1). The ASIR for all cancers combined was higher for
Hispanic males as compared to Hispanic females (ASIR of 163 cases per $10^{6}$ PYs vs. 142 cases per $10^{6}$ PYs), as well as for non-Hispanic white males as compared to non-Hispanic white females (ASIR of 159.8 cases per $10^{6}$ PYs vs. 138.6 cases per $10^{6}$ PYs) (Table 2). Florida Hispanics had a much higher ASIR for all cancers combined compared to their non-Hispanic white counterparts (ASIR of 171.9 cases per $10^{6} \mathrm{PYs}$ vs. 142.5 cases per $\left.10^{6} \mathrm{PYs}\right)$, but this was not true for California Hispanic children (Table 3).

\section{Leukemia}

The ASIR for leukemia was significantly higher for Hispanics (61.5 cases per $10^{6}$ PYs) compared to that for nonHispanic whites (48.8 cases per $10^{6} \mathrm{PYs}$ ), with an SIR of 1.26. The findings were similar for the lymphoid leukemia subgroup, but there was no significant difference in rates for acute nonlymphocytic leukemia between the two race/ ethnic groups. A similar relationship was found for Hispanic children when analyzed by gender, although the ASIR was about 25\% higher for Hispanic male children compared to Hispanic female children. The leukemia rates in the two state populations were similar.

\section{Lymphoma and reticuloendothelial neoplasms}

There was no significant difference overall between Hispanic children and non-Hispanic white children (both states combined) in the incidences of lymphomas and reticuloendothelial 
TABLE 3. Total cancer cases and annual cancer age-standardized incidence rates (ASIRs) per $10^{6}$ person-years for Hispanic and non-Hispanic white children $<15$ years of age, 1988-1998, by state for both genders combined

\begin{tabular}{|c|c|c|c|c|c|c|c|c|c|c|c|c|}
\hline \multirow{2}{*}{$\begin{array}{l}\mathrm{ICCC}^{\mathrm{a}} \text { major diagnostic groups } \\
\text { and selected subgroups }\end{array}$} & \multicolumn{6}{|c|}{ California } & \multicolumn{6}{|c|}{ Florida } \\
\hline & Count & ASIR & $S E^{b}$ & Count & ASIR & SE & Count & ASIR & SE & Count & ASIR & SE \\
\hline All cancers combined & 4462 & 149.9 & 2.2 & 5205 & 153.3 & 2.1 & 735 & 171.9 & 6.4 & 2550 & 142.5 & 2.8 \\
\hline Leukemia & 1845 & 61.9 & 1.4 & 1682 & 50 & 1.2 & 251 & 59.7 & 3.8 & 823 & 46.6 & 1.6 \\
\hline Lymphoid leukemia & 1525 & 51.1 & 1.3 & 1371 & 40.8 & 1.1 & 206 & 49.2 & 3.4 & 653 & 37.1 & 1.5 \\
\hline Non-Hodgkin's lymphoma & 133 & 4.5 & 0.4 & 224 & 6.4 & 0.4 & 40 & 9.0 & 1.4 & 93 & 5.0 & 0.5 \\
\hline Burkitt's lymphoma & 56 & 1.9 & 0.3 & 77 & 2.2 & 0.3 & 18 & 4.1 & 1.0 & 59 & 3.2 & 0.4 \\
\hline $\mathrm{CNS}^{\mathrm{c}}$, misc., intracranial, intraspinal & 675 & 22.6 & 0.9 & 1147 & 33.5 & 1.0 & 128 & 29.7 & 2.6 & 559 & 30.8 & 1.3 \\
\hline Ependymoma & 56 & 1.9 & 0.3 & 97 & 2.9 & 0.3 & 13 & 3.1 & 0.9 & 41 & 2.3 & 0.4 \\
\hline Astrocytoma & 281 & 9.4 & 0.6 & 594 & 17.3 & 0.7 & 57 & 13.3 & 1.8 & 311 & 17.0 & 1.0 \\
\hline PNET $^{d}$ & 212 & 7.1 & 0.5 & 284 & 8.4 & 0.5 & 36 & 8.3 & 1.4 & 137 & 7.6 & 0.7 \\
\hline Malignant bone tumors & 160 & 5.5 & 0.4 & 228 & 6.4 & 0.4 & 48 & 10.3 & 1.5 & 120 & 6.1 & 0.6 \\
\hline Osteosarcoma & 98 & 3.4 & 0.3 & 126 & 3.5 & 0.3 & 31 & 6.6 & 1.2 & 44 & 2.2 & 0.3 \\
\hline Ewing's sarcoma & 48 & 1.6 & 0.2 & 89 & 2.5 & 0.3 & 11 & 2.5 & 0.7 & 68 & 3.5 & 0.4 \\
\hline Soft tissue sarcomas & 285 & 9.6 & 0.6 & 328 & 9.6 & 0.5 & 48 & 11.0 & 1.6 & 149 & 8.2 & 0.7 \\
\hline Rhabdomyosarcoma & 119 & 4.0 & 0.4 & 168 & 5 & 0.4 & 25 & 5.8 & 1.2 & 78 & 4.4 & 0.5 \\
\hline Germ-cell, trophoblastic, other & 224 & 7.6 & 0.5 & 167 & 4.9 & 0.4 & 35 & 7.9 & 1.3 & 78 & 4.3 & 0.5 \\
\hline Carcinomas, other epithelial & 107 & 3.7 & 0.4 & 235 & 6.6 & 0.4 & 10 & 2.1 & 0.7 & 79 & 4.1 & 0.5 \\
\hline Other and unspecified malignancy & 10 & 0.3 & 0.1 & 12 & 0.4 & 0.1 & 6 & 1.4 & 0.6 & 22 & 1.2 & 0.3 \\
\hline
\end{tabular}

a ICCC = International Classification of Childhood Cancer.

${ }^{\mathrm{b}} \mathrm{SE}=$ standard error.

${ }^{\mathrm{C}} \mathrm{CNS}=$ central nervous system.

${ }^{\mathrm{d}} \mathrm{PNET}=$ primitive neuroectodermal tumor .

neoplasms $(\mathrm{SIR}=1.04$, Table 1$)$. The same was true when analyzed by race/ethnicity and gender (both states combined), although male children from both race/ethnic groups had ASIRs that were more than twice those for female children (Table 2). However, when analyzed by state, Hispanic children in Florida had a 50\% higher lymphoma incidence (ASIR = 20.8 cases per $10^{6}$ PYs) compared to California Hispanics (ASIR $=13.5$ cases per $10^{6}$ PYs) (Table 3 ).

The higher incidence rates of Hodgkin's lymphoma in males accounted for most of the gender difference among Hispanics, while higher rates of non-Hodgkin's and Burkitt's lymphoma in males accounted for most of the gender difference among nonHispanic white children. Higher incidence rates of non-Hodgkin's and
Burkitt's lymphoma in Florida's Hispanic children accounted for most of the interstate difference noted above.

\section{Central nervous system tumors}

Hispanic children had a much lower rate for the central nervous system (CNS) tumor group (23.6 cases per $10^{6}$ PYs) compared to non-Hispanic whites (32.6 cases per $10^{6} \mathrm{PYs}$ ), with an SIR of 0.72 . Most of this difference is explained by an incidence rate for astrocytoma in non-Hispanic white children nearly twice that of Hispanics. There were no significant gender differences in CNS tumor group or astrocytoma subgroup incidence rates among Hispanic children. Essentially all of the lower incidence of CNS tumors for Hispanics was explained by the California cases, with no significant difference in CNS tumor incidence found in Florida between Hispanic children and nonHispanic white children.

\section{Sympathetic nervous system tumors}

More than $96 \%$ of the sympathetic nervous system tumors were neuroblastomas or ganglioneuroblastomas. Hispanic children had a lower incidence of these tumors (0.76) compared to non-Hispanic whites. Hispanic male children had higher incidence rates compared to female children. Florida Hispanic children had a nearly 50\% higher incidence of sympathetic nervous system tumors than did California Hispanics. Incidence rates for these tumors for both race/ethnic groups in Florida were essentially the same. 


\section{Retinoblastoma, renal, and hepatic tumors}

Hispanic children had a higher incidence rate of retinoblastoma (SIR = 1.27), but no significant differences in the incidence of renal tumors $(98 \%$ of which were Wilms' tumors) or hepatic tumors were found compared to nonHispanic whites. There were no overall gender differences in the incidence of either retinoblastoma or hepatic tumors among Hispanic children, but Hispanic female children had a onethird higher incidence of renal tumors than did male Hispanics.

Hispanic children in California and those in Florida had similar incidence rates for retinoblastoma, while Florida Hispanics had a $20 \%$ higher incidence of renal tumors. There was a striking difference between California and Florida Hispanic children with respect to hepatic tumors, with California Hispanics having an incidence rate nearly five times that of Florida Hispanic children (ASIR of 2.3 cases per $10^{6}$ PYs vs. ASIR of 0.5 cases per $10^{6}$ PYs, respectively).

\section{Malignant bone tumors}

There was no overall significant difference in the incidence rates of malignant bone tumors between Hispanic children and non-Hispanic white children, although osteosarcoma incidence was significantly higher among Hispanic children, with the reverse being true for Ewing's sarcoma. The higher incidence rate for osteosarcoma in Hispanic children was almost entirely due to the higher incidence among Hispanic female children. The incidence of malignant bone tumors was nearly twice as high for Florida Hispanics as for California Hispanics, with most of the difference due to higher osteosarcoma incidence in Hispanic children in Florida.

\section{Soft tissue sarcomas, germ cell tumors, and carcinomas}

The overall incidence of soft tissue sarcomas was similar for Hispanic children and for non-Hispanic white children; this was also true for the rhabdomyosarcoma subgroup. The results were similar for Hispanic children, both in terms of gender and for the two states. Germ cell and similar tumors had a $60 \%$ higher incidence among Hispanic children (distributed similarly by gender) as compared to non-Hispanic whites for the study cases combined, as well as for each of the state subpopulations. Incidence rates of carcinomas and other epithelial tumors were significantly lower for Hispanic children, particularly males, compared to non-Hispanic white children. This same relationship was found for both state Hispanic subpopulations.

\section{DISCUSSION}

Hispanics have become the largest racial/ethnic subpopulation in the United States. The Hispanic populations of the two study states, California and Florida, represented nearly $40 \%$ of the estimated 35 million Hispanics residing in the United States in 2000 (22). By national origin, the United States Hispanic population is distributed approximately as follows: Mexican, 66\%; Puerto Rican (living outside of Puerto Rico), 9\%; Cuban, 4\%; Central/South American, 15\%; other Hispanic, 6\%. When considered together, the Hispanic populations of California and Florida have a similar national origin distribution to that of the United States: Mexican, 60\%; Puerto Rican, 4\%; Cuban, 6\%; Central/ South American, 22\%; and other Hispanic, $8 \%$.

Compared to the national distribution, the Hispanics from the two study states slightly overrepresent persons of Cuban origin and slightly underrepresent Puerto Rican and Central/South American subgroups. Hispanics in the United States are more likely to live in metropolitan areas than are nonHispanic whites, with Puerto Ricans (outside of Puerto Rico) more likely to live in central city areas, and CubanAmericans more likely to live in metropolitan areas beyond the central city.
About $10 \%$ of Mexican-Americans live in non-metropolitan areas, while for the other national origin subpopulations the figure is less than 5\% (23).

In our study the overall cancer incidence rate among Hispanic children (153 cases per $10^{6} \mathrm{PYs}$ ) did not differ significantly from that of non-Hispanic white children (150 cases per $10^{6} \mathrm{PYs}$ ). This finding is in contrast to recent reports on cancer incidence among adult Hispanics, which have shown an overall cancer incidence that was 20\% lower for Hispanic men and 35\% lower for Hispanic women as compared to their non-Hispanic white counterparts $(10,11)$.

In our study, leukemia, particularly lymphoid leukemia, was more common among Hispanic children than it was among non-Hispanic white children; this was true for Hispanics of both genders and from both states. This finding is consistent with other reports for Hispanic children compared to non-Hispanic white children in the United States $(12,13,15)$. Also, the actual incidence of leukemia in Hispanic children in our study is similar to that reported for Costa Rica, which had the highest incidence of childhood leukemia in a study that had data from more than 50 countries around the world (24).

The higher incidence of Hodgkin's lymphoma among Hispanic children is consistent with previously reported results from Costa Rica and Mexico (25-27). Although the incidence of non-Hodgkin's lymphoma was not statistically different between Hispanic children and non-Hispanic white children for all our study cases combined, there was a striking difference between Hispanic children in California and those in Florida. The incidence of 9 cases per $10^{6}$ PYs for Florida Hispanic children was twice that of California. Cuba has some of the highest reported rates of nonHodgkin's lymphoma in the world, with somewhat elevated rates also reported for Costa Rica and Spain (24, 25). Reports from the states of New Mexico and Texas (both located in the southwestern United States, and with a majority of the Hispanics in them 
being of Mexican origin) do not show this difference $(12,13)$. Instead, New Mexico and Texas have rates that are very similar to the ones for California's Hispanic children. Therefore, it may be the difference in the distribution of national origins among Hispanics from Florida (primarily from Cuba and Central America) that accounts for this difference in pediatric nonHodgkin's lymphoma incidence rates.

Compared to non-Hispanic whites, the Hispanic children in our study had a lower incidence of central nervous system tumors, particularly astrocytomas. By a similar magnitude, the incidence rate for sympathetic nervous system tumors was also lower among Hispanic children than among nonHispanic whites. Both of these results are consistent with other reports on cancer among Hispanic children (12, $13,24,28)$. Once again in our study there was a marked interstate difference, with Florida's Hispanic children having higher incidence rates for both CNS tumors $(+31 \%)$ and sympathetic nervous system tumors $(+46 \%)$ compared to California's Hispanic children. Whether these differences are due to different national origin distributions, environmental differences, or other exposure differences between the two states cannot be determined from this study, but it is an interesting potential area for further research.

Compared to their non-Hispanic white counterparts, the Hispanic children in our study had higher incidence rates for retinoblastoma tumors $(+27 \%)$ and for germ cell tumors $(+62 \%)$. That higher incidence of germ cell tumors in Hispanic children is in interesting contrast to a finding that we researchers had reported earlier, of a $60 \%$ lower incidence for testicular cancer among Hispanic adult men living in southern Florida as compared to non-Hispanic white men in that part of the state (10). In this study the incidence of osteosarcoma was about 30\% higher among the Hispanic children than among the non-white Hispanic children in the two states. However, most of that difference was accounted for by an incidence rate among the Florida Hispanic children that was nearly twice that of both
Hispanics and non-Hispanic whites in California and three times that of nonHispanic whites in Florida. A similar pattern was found for Ewing's sarcoma. The higher incidence rates for non-Hodgkin's lymphoma, CNS tumors, sympathetic nervous system tumors, and malignant bone tumors were responsible for the overall higher cancer incidence among Hispanic children in Florida compared to their counterparts in California.

Hispanic children in California had a markedly higher incidence rate for one of the less common pediatric tumors, hepatoblastoma, compared to Florida Hispanics. Risk factors for hepatoblastoma may include genetic and prenatal exposures such as parental occupational exposures associated with manufacturing and the petrochemical industry (29). Certain areas of northern Mexico and southern California are more industrialized than is southern Florida, where most of that state's Hispanics reside. Because the cancer registries do not have parental data, such as occupation and family history, further study into the reasons for the interstate difference in hepatoblastoma incidence in terms of genetic or prenatal factors cannot be made using this study's database.

Perhaps the main potential source of error in this study is the categorization of certain children with cancer as "Hispanic." Certainly, the term "Hispanic," as applied to the population of the United States, encompasses a heterogeneous population in terms of genetics, as well as birth nation ("Hispanic" includes both persons born in the United States and immigrants from various nations), assimilation, socioeconomics, and physical environment $(30,31)$. Indeed, when controlling for some of these factors (such as socioeconomic status), the magnitude of ethnicity as a risk factor may be markedly reduced $(32,33)$. This suggests that ethnicity may serve as a potential confounder for other factors, including the ones listed above. Indeed, it has been suggested that most cancer risk among immigrant populations and their offspring is environmental in etiology (34). Also, ethnic classification is prone to possible misclassification, even with the use of additional measurements such as Spanish surname (35-37). The potential for misclassification is particularly problematic for children, where either self-reported ethnicity and/or surname may not accurately reflect the true ethnicity of both parents. Different data sets, including cancer registries, may use different definitions of ethnicity. For that reason, in our study of California and Florida children we recoded Hispanic ethnicity using a common categorical definition.

This study has several other potential limitations. Pediatric cancer is a relatively rare event and is not distributed normally. Also, case-finding, although excellent in both cancer registries in this report, is never $100 \%$ complete and accurate, particularly when applied to undocumented or highly mobile subpopulations such as seasonal agricultural workers. For these reasons, although this data set is considered to be population-based, 95\% confidence intervals have been constructed around the reported point estimates in order to reflect possible sample variation. Finally, the Hispanic population denominators may undercount the actual population in terms of undocumented residents. (The $\mathrm{Na}$ tional Center for Health Statistics uses complex statistical methodologies to estimate the number of undocumented residents. Estimates of undocumented Hispanic residents range up to 2000000 in California (20\% of California Hispanics) and more than 300000 in Florida ( $12 \%$ of Florida Hispanics). However, the precision of these estimates is unknown.) Nevertheless, we believe that given the relative rarity of pediatric cancer and the use of 11 years of data, any undercounts would not substantively affect the conclusions presented here.

The Hispanic children in California and Florida represent nearly one-third of Hispanic children in the United States. Further, they encompass the full range of national origin, generation of residence, urban versus rural residence, socioeconomic status, and educational status seen among His- 
panics in the United States as a whole. The large sample size used in this study would appear to accurately describe the incidence of pediatric cancer among Hispanic children in the United States who were less than 15 years of age. Overall, from these results, these Hispanic children appear to have the same overall cancer incidence as non-Hispanic white children. However, some important differences in incidence for certain tumor groups were identified and described earlier in this article. One of the purposes of descriptive epidemiological studies such as this one is to identify associations from which hypotheses may be formed about potential exposuredisease relationships. The interstate differences in cancer incidence noted among Hispanic children from California and Florida for non-Hodgkin's lymphoma, CNS tumors, sympathetic nervous system tumors, and malignant bone tumors are examples of such associations. These findings may lead to etiologic hypotheses that could be tested by future analytic epidemiological studies.

Hispanic ethnicity may be a confounder for other risk factors such as familial, socioeconomic, environmental, and parent-occupational exposures. In addition, the Hispanic population in the United States is heterogeneous and dynamic in terms of national origin and ongoing immigration and assimilation. Therefore, we conclude that future studies of childhood cancer in Hispanic populations of the United States should directly explore these potential risk factors, and additionally include the application of newer molecular and genetic epidemiological methods such as identification of biomarkers for carcinogenic exposures, inherited genes for cancer susceptibility, and biomarkers of early exposure effects.

Acknowledgements. The authors would like to thank the staff and abstractors of the California Cancer Registry and the Florida Cancer Data System, as well as the respective states' Departments of Health and the United States Centers for Disease Control and Prevention, for making this study possible.

\section{REFERENCES}

1. Robison LL. General principles of the epidemiology of childhood cancer. In: Pizzo PA, Poplack DG, eds. Principles and practice of pediatric oncology. Philadelphia: LippincotRaven Publishers; 1997. Pp. 1-10.

2. Jemal A, Thomas A, Murray T, Thun M. Cancer statistics, 2002. CA Cancer J Clin. 2002;52: 23-47.

3. Ross JA, Severson RK, Pollock BH, Robison LL. Childhood cancer in the United States: a geographical analysis of cases from the Pediatric Cooperative Clinical Trials Groups. Cancer. 1996;77:201-7.

4. Trapido EJ, McCoy CB, Stein NS, Engel S, Zavertnik JJ, Comerford M. Epidemiology of cancer among Hispanic males: the experience in Florida. Cancer. 1990;65:1657-62.

5. Trapido EJ, McCoy CB, Stein NS, Engel S, McCoy HV, Olejniczak S. The epidemiology of cancer among Hispanic women: the experience in Florida. Cancer. 1990;66:2435-41.

6. Trapido EJ, Burciaga Valdez R, Obeso JL, Strickman-Stein N, Rotger A, Perez-Stable EJ. Epidemiology of cancer among Hispanics in the United States. J Natl Cancer Inst Monogr. 1995;(18):17-28.

7. Horm JW, Devesa SS, Burhansstipanov L. Cancer incidence, mortality, and survival among racial and ethnic minority groups in the United States. In: Schottenfeld D, Fraumeni JF, eds. Cancer epidemiology and prevention. New York: Oxford University Press; 1996. Pp. 192-235.

8. Canto AG, Chu F. Cancer incidence rates among Hispanics. Cancer. 2000;88:2642-52.

9. Underwood SM. Minorities, women, and clinical cancer research: the charge, promise, and challenge. Ann Epidemiol. 2000;10:S3-12.
10. Wilkinson JD, Wohler-Torres B, Trapido E, Fleming LE, MacKinnon J, Voti L, et al. Cancer trends among Hispanic men in South Florida, 1981-1998. Cancer. 2002;94:1183-90.

11. Wilkinson JD, Wohler-Torres B, Trapido E, Fleming LE, MacKinnon J, Peace S. Cancer among South Florida's Hispanic women: an 18-year assessment. Cancer. 2002;95:1752-8.

12. Duncan MH, Wiggins CL, Samet JM, Key CR. Childhood cancer epidemiology in New Mexico's American Indians, Hispanic whites and non-Hispanic whites, 1970-1982. J Natl Cancer Inst. 1986;76(6):1013-8.

13. Weiss NS, Katz JA, Frankel LS, Lloyd LE, McClain KL, Torges $\mathrm{K}$, et al. Incidence of childhood and adolescent cancer in Texas. Texas Med. 1996;92:54-60.

14. Glazer ER, Perkins CI, Young JL, Schlag RD, Campleman SL, Wright WE. Cancer among Hispanic children in California, 1988-1994. Cancer 1999;86:1070-9.

15. Wilkinson JD, Fleming LE, MacKinnon J, Voti L, Wohler-Torres B, Peace S, et al. Lymphoma and lymphoid leukemia incidence in Florida children: ethnic and racial distribution. Cancer. 2001;91:1402-8.

16. United States Census Bureau. The Hispanic population in the United States, March 2000 [Web page]. Available from: http://www. census.gov/population/socdemo/hispanic/ p20-535/p20-535.pdf. Accessed 5 June 2005.

17. United States Census Bureau. American factfinder [Web page]. Available from: http:// factfinder.census.gov/servlet/Basic FactsServlet. Accessed 10 September 2003.

18. United States Census Bureau. Profiles of general demographic characteristics 2000 [Web page]. Available from: http://www.census. gov/prod/cen2000/dp1/2kh12.pdf. Accessed 20 May 2002.

19. North American Association of Central Cancer Registries. NAACCR registry certification [Web page]. Available from: http://www. naaccr.org/index.asp?Col_SectionKey $=12 \&$ Col_ContentID=244. Accessed 27 September 2004.

20. Kramarova E, Stiller CA. The international classification of childhood cancer. Int J Cancer. 1996;68:759-65.

21. Breslow NE, Day NE. Statistical methods in cancer research. Vol. 2. The design and analysis of cohort studies. Lyon: International Agency for Research on Cancer; 1987.

22. United States, Department of Commerce. Profile of general demographic characteristics 2000. Available from: http:/ / www.factfinder. census.gov. Accessed 20 February 2004.

23. United States, Department of Commerce. US Census Bureau, Current Population Survey, March 2002, Ethnic and Hispanic Statistics Branch, Population Division [Web page]. Available from: http://www.census.gov/ population/socdemo/hispanic/ppl-165/ tab20-2.pdf. Accessed 20 February 2004.

24. Parkin DM, Stiller CA, Draper GJ, Bieber CA. The international incidence of childhood cancer. Int J Cancer. 1988;42:511-20.

25. Stiller CA, Parkin DM. Geographic and ethnic variations in the incidence of childhood cancer. Br Med Bull. 1996;52(4):682-703.

26. Fajardo-Gutiérrez A, Navarrete-Martínez A, Reynoso-García M, Zarzosa-Morales ME, Mejía-Aranguré M, Yamamoto-Kimura LT. Incidence of malignant neoplasms in children attending Social Security hospitals in Mexico City. Med Pediatr Oncol. 1997;29:208-12. 
27. Mendoza-Sanchez HF, Quintana-Sanchez JA, Rivera-Marquez H, Mejia-Dominguez AM, Fajardo-Gutierrez A. Epidemiology of lymphomas in children residing in Mexico City. Arch Med Res. 1998;29:67-73.

28. Breslow NE, Langholz B. Childhood cancer incidence: geographical and temporal variations. Int J Cancer. 1983;32:703-16.

29. United States, National Institutes of Health, National Cancer Institute. Cancer incidence and survival among children and adolescents: United States SEER Program 1975-1995 [Web site]. Available from: http://seer.cancer. gov/publications/childhood/hepatic.pdf. Accessed 20 February 2004.

30. United States, Department of Commerce. Profiles of general demographic characteristics 2000 [Web site]. Available from: http:/ / www. census.gov/prod/cen2000/dp1/2kh12.pdf. Accessed 6 June 2001.

31. Villar HV, Menck HR. The National Cancer Database report on cancer in Hispanics. Cancer. 1994;74:2386-95.

32. Modiano MR, Villar-Werstler P, Meister J, Figueroa-Valles N. Cancer in Hispanics: issues of concern. J Natl Cancer Inst Monogr. 1995;(18):35-9.

33. Lin SS, Kelsey JL. Use of race and ethnicity in epidemiologic research. Epidemiol Rev. 2000; 22(2):187-202.

34. Colditz GA. Cancer culture: epidemics, human behavior, and the dubious search for new risk factors. Am J Public Health. 2001; 91(3):357-9.

35. Stewart SL, Swallen KC, Glaser SL, Horn-Ross PL, West DW. Adjustment of cancer incidence rates for ethnic misclassification. Biometrics. 1998;54:774-81.

36. Swallen KC, West DW, Stewart SL, Glaser SL, Horn-Ross PL. Predictors of misclassification of Hispanic ethnicity in a population-based cancer registry. Ann Epidemiol. 1997;7(3): 200-6.

37. Perez-Stable EJ, Hiatt RA, Sabogal F, OteroSabogal R. Use of Spanish surnames to identify Latinos: comparison to self-identification. J Natl Cancer Inst Monogr. 1995;(18):11-5.

Manuscript received 13 October 2004. Manuscript accepted for publication 6 April 2005.

RESUMEN Objetivo. Comparar de manera directa la incidencia de cáncer en niños hispanos y en niños blancos no hispanos en los estados de California y la Florida, donde viven casi las dos terceras partes de toda la población infantil hispana de Estados Unidos de América.

\section{La incidencia de cáncer en niños hispanos en Estados Unidos}

Métodos. Del Sistema de Estadísticas de Cáncer de la Florida (Florida Cancer Data System) y del Registro de Cáncer de California (California Cancer Registry) se sacaron datos transversales de 1988 a 1998 correspondientes a todos los casos nuevos de cáncer en niños ( $<15$ años de edad), codificados según raza u origen étnico en "hispanos" o "blancos no hispanos". Los resultados se expresaron en forma de tasas de incidencia estandarizadas por edad, usando como referencia la población mundial estándar en millones de habitantes. Se comparó la frecuencia de cáncer en niños hispanos y en niños blancos no hispanos mediante razones de incidencia estandarizadas (RIE) y sus respectivos intervalos de confianza del 95\% (IC95\%).

Resultados. Al compararse la frecuencia de todos los tipos de cáncer en niños hispanos y niños blancos no hispanos, la RIE fue de 1,02 (IC95\%: 0,99 a 1,05). Al examinarse ciertos tipos de tumores en particular, las RIE apuntaron a mayores tasas de incidencia de leucemia ( $\mathrm{RIE}=1,26$; IC95\%: 1,19 a 1,34), linfoma de Hodgkin (RIE = 1,29; IC95\%: 1,08 a 1,54), y tumores de células germinativas (RIE = 1,62; IC95\%: 1,34 a 1,96) en niños hispanos. Estos últimos tuvieron menores incidencias de tumores del sistema nervioso central (RIE $=0,72$; IC95\%: 0,66 a 0,78 ) y de tumores del sistema nervioso simpático (RIE =0,76; IC95\%: 0,66 a 0,87). En lo que respecta a diferencias entre estados, la incidencia de linfoma, de tumores del sistema nervioso central, de tumores del sistema nervioso simpático y de tumores óseos malignos fue mayor entre jóvenes hispanos residentes de la Florida; en cambio, la incidencia de hepatomas malignos fue mayor entre jóvenes hispanos residentes de California.

Conclusiones. Aunque la incidencia general de cáncer en niños hispanos fue semejante a la observada en niños blancos no hispanos, se hallaron diferencias significativas en el caso de ciertos tumores en particular. Habida cuenta de que ser hispano puede ser un factor de confusión en relación con otros factores de riesgo de cáncer (familiares, socioeconómicos o ambientales), se recomienda explorar estos últimos factores en futuras investigaciones sobre el riesgo de cáncer en niños hispanos.

Palabras clave Neoplasmas, hispanoamericanos, Estados Unidos. 